\title{
EXPERIMENTAL AND NUMERICAL CRACK INITIATION ANALYSIS OF THE COMPRESSOR BLADES WORKING IN RESONANCE CONDITIONS
}

\author{
Lucjan Witek \\ Rzeszów University of Technology \\ Rzeszów, Poland
}

\begin{abstract}
This paper presents the results of a complex experimental and numerical crack initiation analysis of the helicopter turbo-engine compressor blades subjected to vibrations. A nonlinear finite element method was utilized to determine the stress state of the blade during the first mode of transverse vibration. In this analysis, the numerical models without defects as well as those with $V$-notches were defined. The quality of the numerical solution was checked by the convergence analysis. The obtained results were next used as an input data into crack initiation $(\varepsilon-N)$ analyses performed for the load time history equivalent to one cycle of the transverse vibration. In the fatigue analysis, the different methods such as: Neuber elastic-plastic strain correction, linear damage summation and Palmgreen-Miner rule were utilized. As a result of $\varepsilon-N$ analysis, the number of load cycles to the first fatigue crack appearing in the compressor blades was obtained. Moreover, the influence of the blade vibration amplitude on the number of cycles to the crack initiation was analyzed. Values of the fatigue properties of the blade material were calculated using the Baumel-Seeger and Muralidharan methods. The influence of both the notch radius and values of the UTS of the blade material on the fatigue behavior of the structure was also considered. In the last part of the work, the finite element results were compared with the results of experimental vibration HCF tests performed for the compressor blades.
\end{abstract}

\section{INTRODUCTION}

High Cycle Fatigue failures typically have a root cause which stems from flaws in the material (impurities or voids), abusive machining creating high stress concentrations, or wear between components. However, even "perfect" components have finite lives, and will fail after a certain number of cycles. If a problem arises in the compressor section, it will significantly affect the whole engine function and, of course, safety of the aircraft. The broken blade could cause a puncture in the engine casing. Failures of any high speed rotating components (jet engine rotors, centrifuges, high speed fans, etc.) can be very dangerous to passengers, personnel and surrounding equipment and must always be avoided.

The failure analysis of the compressor blade has been the focus of several investigations. The problem of fatigue fracture of the compressor blade was described by: Lourenco et al. [1], Kermanpur et al. [2], Silveira et al. [3], Poznanska et al. [4]. The stress and failure analysis of the compressor blades were also described in [5-6]. The exploitation conditions of the turbine blade are hard due to occurrence of the thermal and mechanical stress, thermal degradation of material, creep, erosion etc. The turbine blade damage caused by these factors is reported in many works: 
(Troshchenko et al. [7], Park et al. [8], Song et al. [9], Vardar et al. [10], Xu et al. [11], Xiaolei et al. [12], Xie et al. [13], and [14, 15]).

This work is the continuation of research [6] in which undamaged blades were tested in the fatigue conditions. The main objective of the presented investigations is to determine both the stress state and the number of fatigue cycles to the first crack appearance in the compressor blades (without defects and also including an artificially created V-notch), subjected to separate high cycle fatigue. These defects (notches) simulate blade damage caused by foreign objects. The numerical results were compared with the results of experimental fatigue testing performed for the first stage compressor blades of the helicopter turbo engine.

\section{FIRST STAGE COMPRESSOR BLADE}

The compressor blade (Figs. 1a and 1b) is susceptible to foreign object damage (FOD). The ingestion of foreign objects into aircraft jet engines can lead to severe structural damage of the fan or compressor airfoils. The high airflow required to operate such engines creates a powerful suction effect which tends to draw in small objects from the area around the aircraft.

Damage to the compressor blades of the engine is normally caused when a particle is hit by the rotating blade. High relative velocity due to the motion of the blade and acceleration of the particle causes high forces and local damage to the blade. This damage is often at or close to the attack (leading) edge of the compressor blade and takes the form of a dent or notch in the leading edge (Fig. 1c). Foreign object damage is a prime reason for maintenance and reparation of military jet engines which operate on landing grounds. The damage induced by the millimeter-size hard objects in conjunction with the typical load spectra experienced by airfoils can lead to nonconservative life prediction and unexpected fatigue failures.
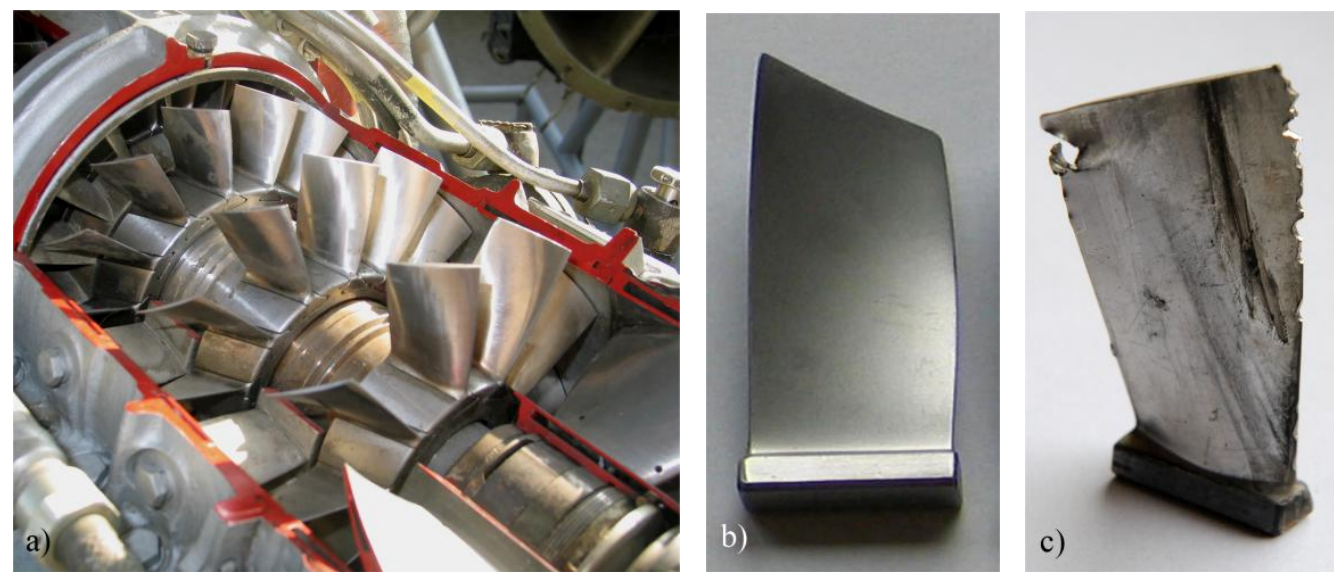

Fig. 1 View of the first stages of aeroengine axial compressor (a), separated blade without mechanical defects (b)and blade after foreign object damage (c)

The first stage blade of the PZL-10W turbo engine (Fig. 1a) is made from EI-961 steel (0.11C; $11 \mathrm{Cr} ; 1.5 \mathrm{Ni}, 1.6 \mathrm{~W} ; 0.18 \mathrm{~V} ; 0.35 \mathrm{Mo} ; 0.025 \mathrm{~S} ; 0.03 \mathrm{P}$ ) with the following properties (measured in temperature $20^{\circ} \mathrm{C}$ ): Ultimate tensile strength $900-1090 \mathrm{MPa}$ (depending on heat treatment), Yield stress 800-900 MPa, Young modulus $200 \mathrm{GPa}$, Poisson ratio 0.3. 


\section{NUMERICAL MODELS OF THE COMPRESSOR BLADES}

Parametric geometry models of the blade were made using the MSC-Patran program [16]. The finite element (FE) models used in this work can be divided into two groups. The first group consists of the models which do not have any defects. In this group, the different numbers of finite elements were used. For example, the model presented in Fig. 2a consists of 60477 nodes and 13440 HEX-20 elements. The HEX-20 isoparametric finite element has quadratic shape functions and gives a good convergence of the numerical solution.
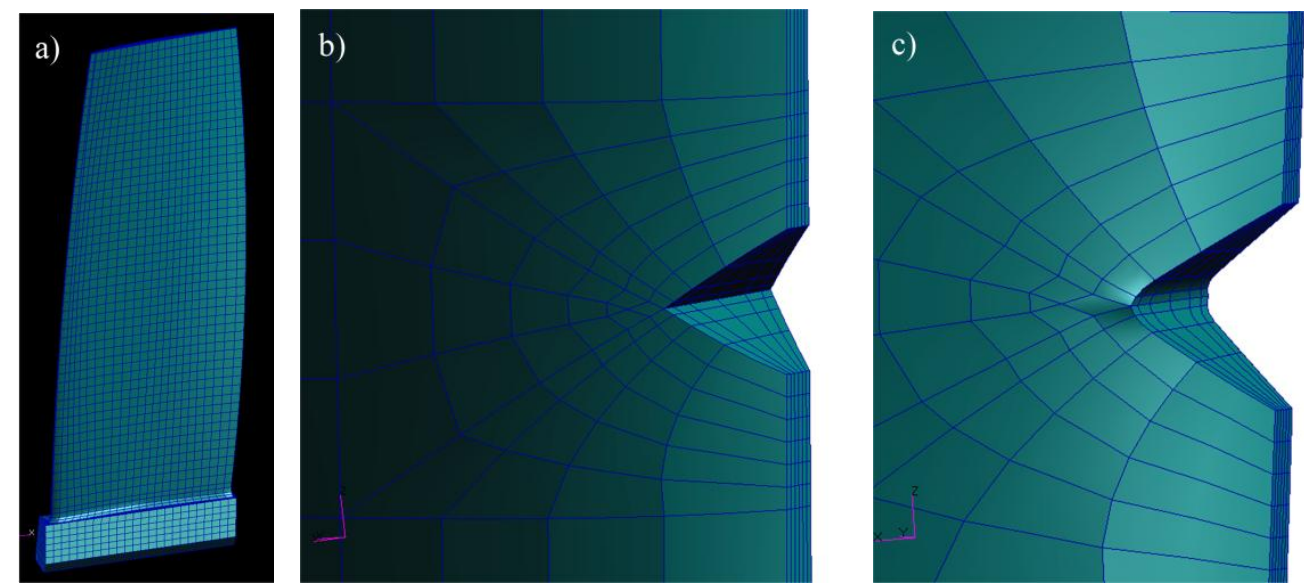

Fig. 2. Numerical model of the non-defected blade (a) and magnified view of model with infinite (b) and finite radius of notch $(c)$

A few blades with different notch radiuses belong to the second group of FE models (Figs. 2b and $2 \mathrm{c}$ ). In the stress and fatigue analysis, models with the following notch radiuses: $0 \mathrm{~mm} ; 0,02$ $\mathrm{mm}$ and $0,075 \mathrm{~mm}$ were considered. The V-notch in the FE model was located about $5 \mathrm{~mm}$ above the blade locking piece (dovetail) (Fig. 3a). During analysis the blade was fixed on the bottom surface of the dovetail.
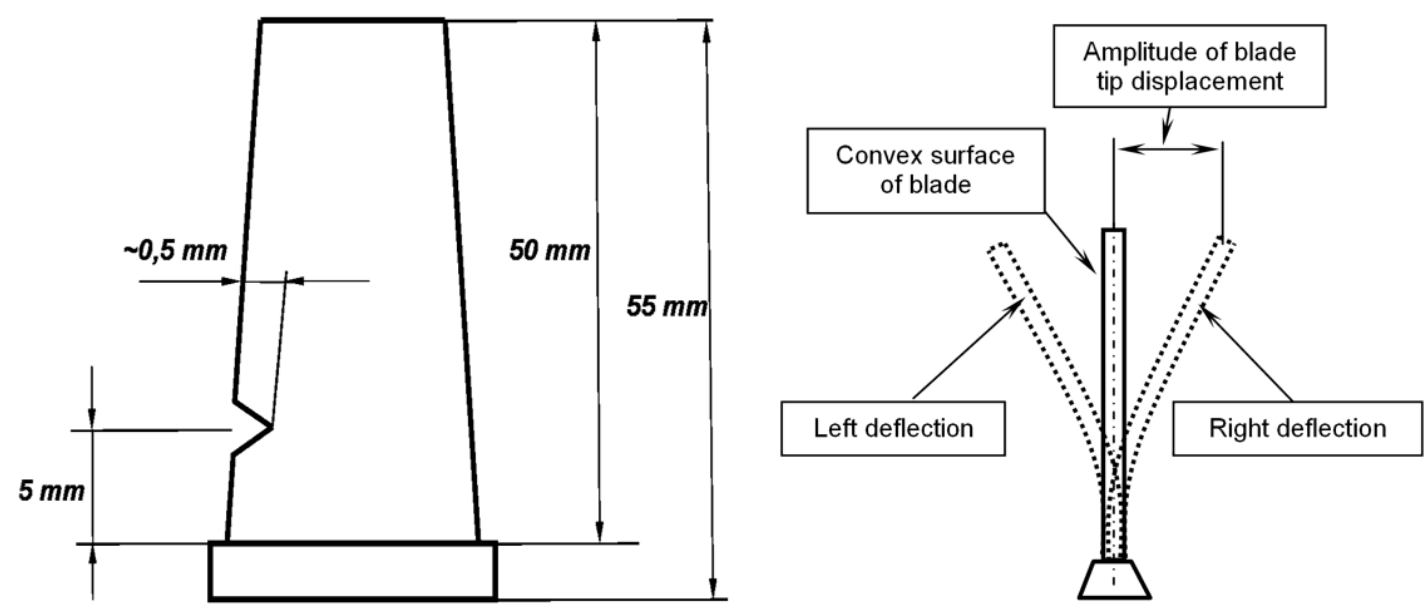

Fig.3. Dimensions of the blade with the notch location (a) and passing positions of blade under transverse vibration (I-mode, view from direction of the blade attack edge)(b)

The blade under vibration is periodically bent towards left and right side (Fig. 3b). Because of the fact that the cross-section of the blade is non-symmetric, the stress levels under left and right deflection of the blade will be quite different. The information about blade deflection will be given in the description of the figures and results. 


\section{FREE VIBRATION ANALYSIS OF THE FIRST STAGE COMPRESSOR BLADE AND THE AMPLITUDE-TIME CHARACTERISTICS FOR THE BLADE AT DIFFERENT STAGES OF FATIGUE DAMAGE}

In the first part of the investigations, a free vibration analysis was performed to obtain the resonant frequencies $f_{\text {rez }}$ and vibration modes for the non-defected blades. These blades consisted of different numbers of finite elements. In further analysis only the first mode of transverse vibration will be considered.

The quality of the FEM solution depends on many factors. One of the main factors is the number of finite elements used for creating the model. The main index during the convergence analysis was value of the resonant frequency (I-st mode) obtained from calculations. The results of the convergence analysis are presented in Fig. 4. The value of the resonant frequency for the model which consists of about $2500 \mathrm{HEX}-20$ elements is equal $814 \mathrm{~Hz}$. When the number of elements in the numerical model grows, the resonant frequency decreases. The value of $f_{\text {rez }}$ approaches a limit of about $788 \mathrm{~Hz}$. Thus, in the presented case the satisfactory results can be obtained when the model has more elements than 13000. However, the maximum number of FE must be finite because it is limited by the computational power of a workstation. Values of $f_{\text {rez }}$ (obtained from experimental investigations) were in the range of $770-790 \mathrm{~Hz}$ [6].

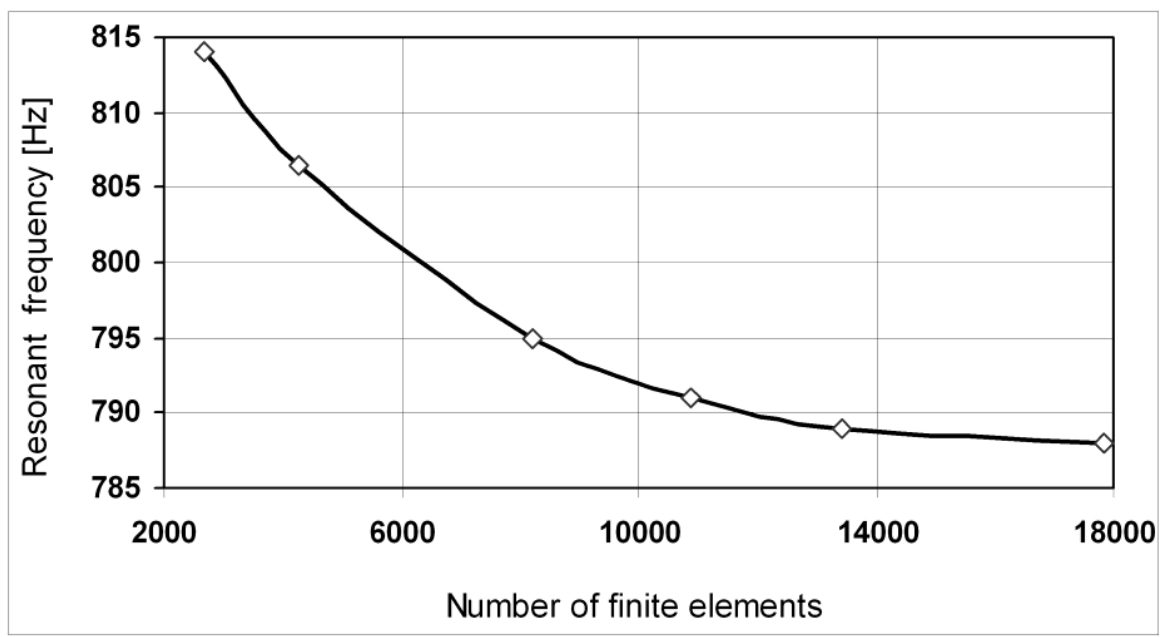

Fig. 4. Resonant frequency in function of the total number of finite element used in the numerical model of the blade without preliminary defect

During experimental dynamic analysis of the blade at different stages of the fatigue fracture, some interesting observations were achieved. The blade tip displacement (vibration amplitude) was measured using the laser scanning vibrometer. When the blade has no defects, the timeamplitude characteristic presented in Fig. 5a has a symmetric shape. When the blade has a 2,5 mm long crack (initiated from the convex blade surface), then the time-amplitude characteristic is not symmetric. The large slope of the curve is observed on the left part of the diagram. The change in excitation rate during the test was equal $1 \mathrm{~Hz} / \mathrm{s}$ (Hertz per second). The search for the resonance (Figs. 5a and 5b) was started from frequency of $740 \mathrm{~Hz}$ (time $=0 \mathrm{~s}$ ). The test was finished at 780 $\mathrm{Hz}$ (time $=40 \mathrm{~s}$ ). As seen from Fig. 5a, the resonance frequency for blade no. 3 is equal $771 \mathrm{~Hz}$. When the blade has a small crack $(2,5 \mathrm{~mm})$, then the resonance frequency is only $1 \mathrm{~Hz}$ lower than for the non-defected blade.

The test in Fig. 5c was started from frequency $650 \mathrm{~Hz}(0 \mathrm{~s})$ and finished at $700 \mathrm{~Hz}(50 \mathrm{~s})$. The value of $\mathrm{f}_{\text {rez }}$ for the blade including $10 \mathrm{~mm}$ long crack is about $665 \mathrm{~Hz}$. On the time-amplitude plot, a snap effect is visible, characteristic for the structure with a large flaw. This effect appears because the blade during resonance test is partially broken as a result of high vibration amplitude. 


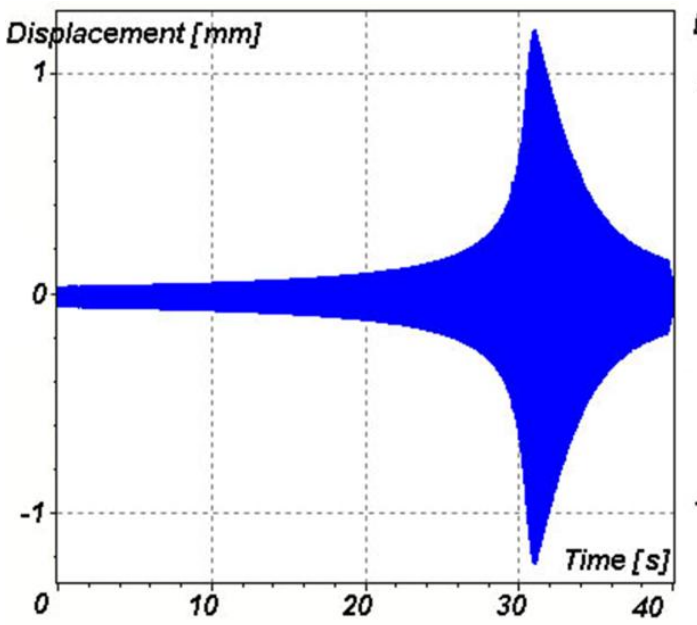

a)

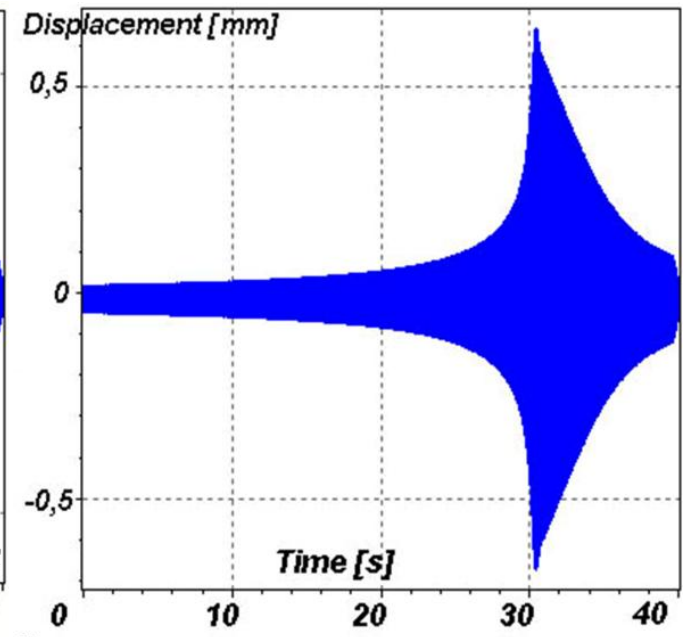

b)

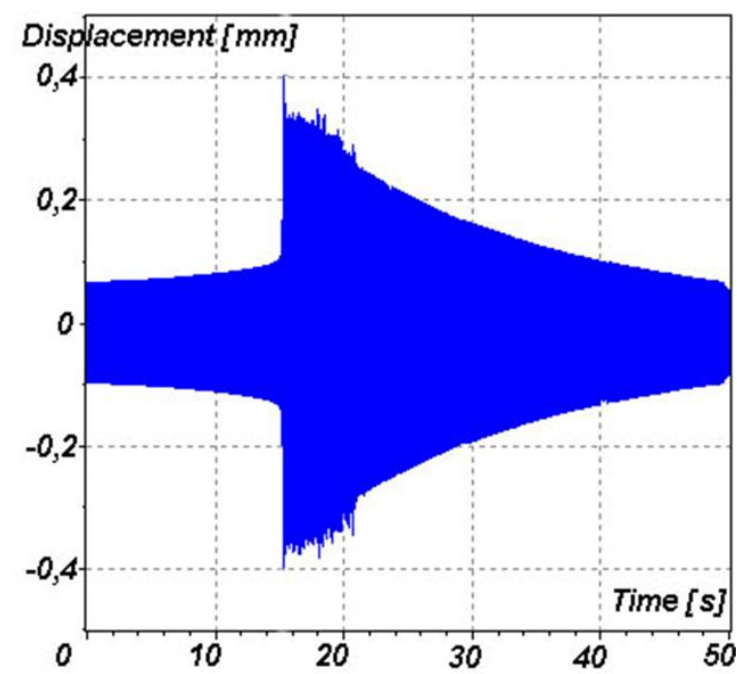

c)

Fig. 5. Amplitude of the blade tip displacement in function of time, for the blade without defect (a), for the blade with the crack length equaled $2,5 \mathrm{~mm}$ and for the blade including $10 \mathrm{~mm}$ crack (c). Intensity of excitation: 2,5 , blade no. 3 .

\section{STRESS ANALYSIS OF THE FIRST STAGE COMPRESSOR BLADES WITHOUT PRELIMINARY DEFECTS}

The Von Mises stress distribution does not show if the material is tensioned or compressed. Owing to this fact, the maximum principal stress $\left(\sigma_{1}\right)$ distributions were analyzed in this paper. This stress is particularly interesting from the point of view of the fatigue strength because it is the tensile stresses that contribute the most significantly to the fatigue crack initiation and, subsequently, to crack propagation. The values of $\sigma_{1}$ stresses obtained from preliminary calculations will be used as an input data in the fatigue crack initiation analysis.

Figs. 6a and 7 show that the highest tensile stress area is located on the convex surface of the blade, where the profile is connected to the dovetail. When the amplitude of the blade tip displacement equals $1 \mathrm{~mm}$, the stress during the right deflection of the blade achieves $248 \mathrm{MPa}$. A bit lover value of the tensile stresses (192-211 MPa) is observed in the zone located between $1 \mathrm{~mm}$ and $15 \mathrm{~mm}$ above the dovetail, in the central part of the convex blade surface. In this zone, a large number of fatigue cracks in the compressor blades were observed in the experiment $[4,5,6]$. Near the neutral axis of the blade cross-section, tensile stress decreases to $0 \mathrm{MPa}$. Between the maximum stress region and the neutral axis, the high gradient of stresses is observed. 
During the left deflection, the maximum tensile stress area $(238 \mathrm{MPa})$ is located near the attack edge of the blade, where the profile is connected to the dovetail (Fig. 6b). In this zone, fatigue cracks were also observed, especially in the blades which have corrosion pits or FOD [5].
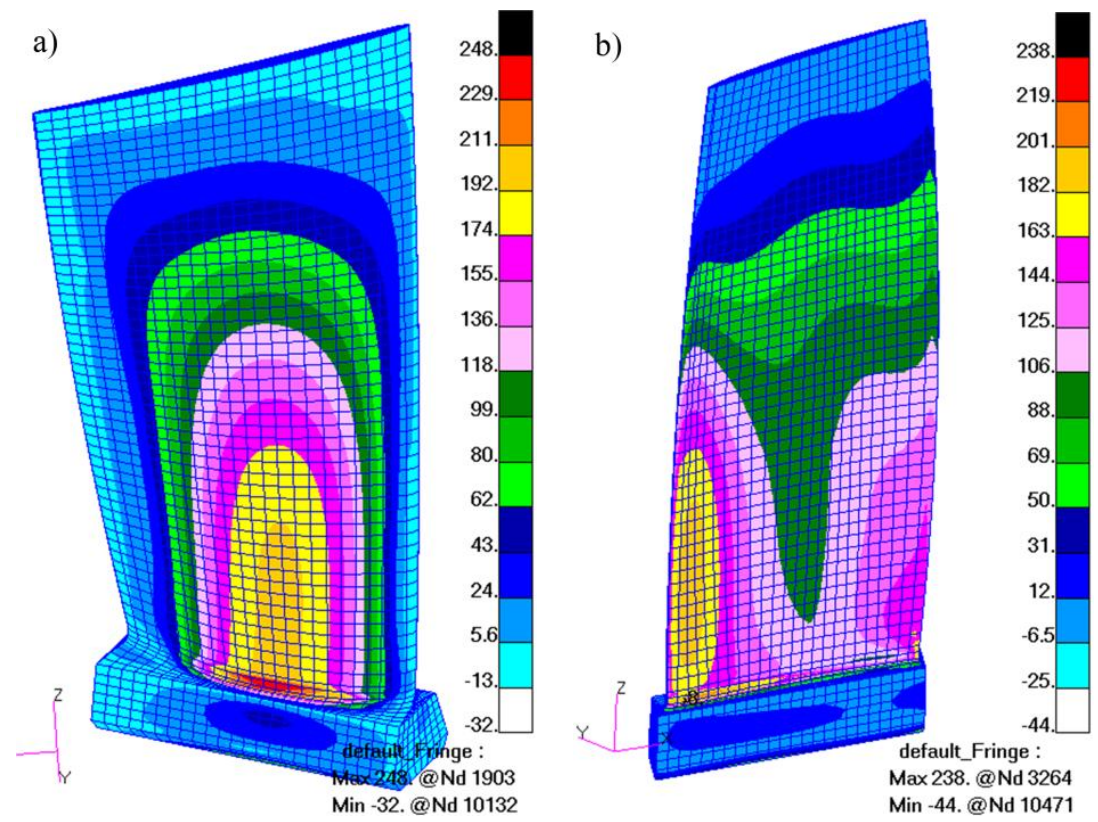

Fig. 6. Maximum principal stress distribution for the blade during resonance (I-st mode of transverse vibrations, amplitude of blade tip $1 \mathrm{~mm}$ ). Right deflection of the blade, view on the convex side of profile (a) and the left deflection, concave side (b)

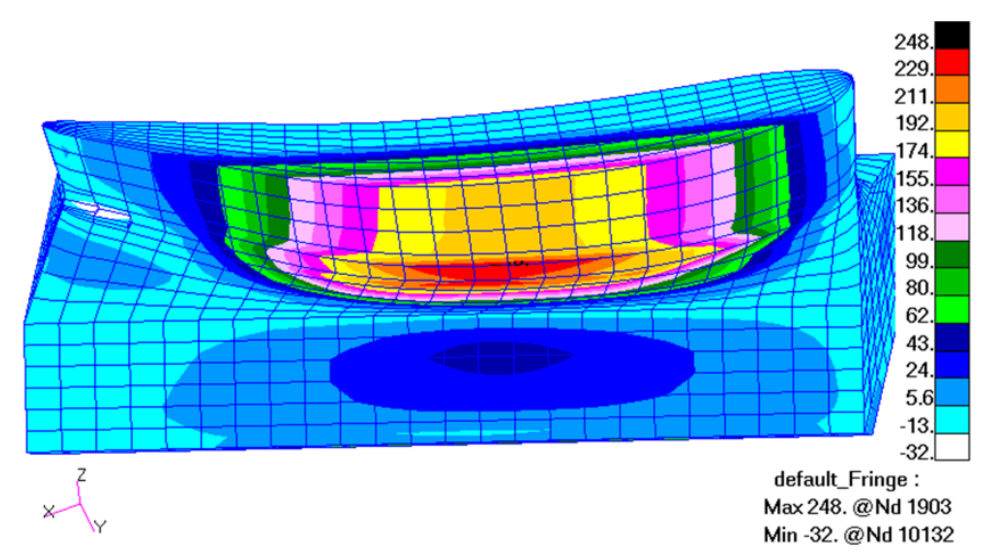

Fig. 7. Maximum principal stress distribution in cross-section of the blade $5 \mathrm{~mm}$ above the dovetail (I-st mode, transverse vibrations, amplitude of blade tip: $1 \mathrm{~mm}$, right deflection)

\section{STRESS ANALYSIS OF COMPRESSOR BLADES WITH NOTCHES}

At the next stage of the stress analysis, the blades with the following $\mathrm{V}$-notch radiuses were considered: $0 \mathrm{~mm}, 0,025 \mathrm{~mm}, 0,05 \mathrm{~mm} ; 0,075 \mathrm{~mm}$ and $0,1 \mathrm{~mm}$. The notch radius equaling zero is the worst case as the highest stress is observed here. A notch with a finite radius can be created by small objects such as oval stones, sand grains etc. However, a defect of the radius close to zero is possible to be obtained when a sharp object such as a piece of the engine casing, part of the aircraft or a sharp stone gets into the engine air intake.

Figure 8 shows that the $\sigma_{1}$ stress in the notch zone achieves $878 \mathrm{MPa}$ (for the blade is passing left under vibration). During the right deflection of the blade, the $\sigma_{1}$ stress value near the notch tip 
is $-282 \mathrm{MPa}$ (Fig. 9). The negative result means that the neutral axis of blade cross-section is above the notch and, in consequence, during the right deflection the notch area is compressed.

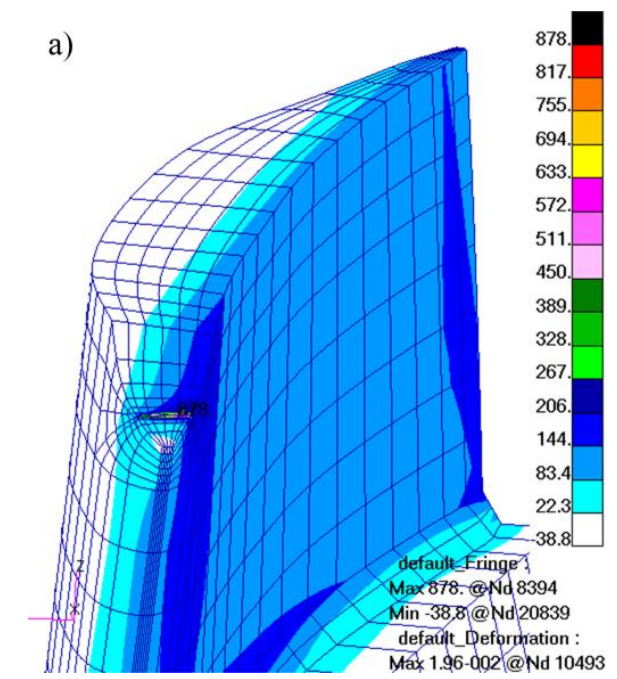

b)

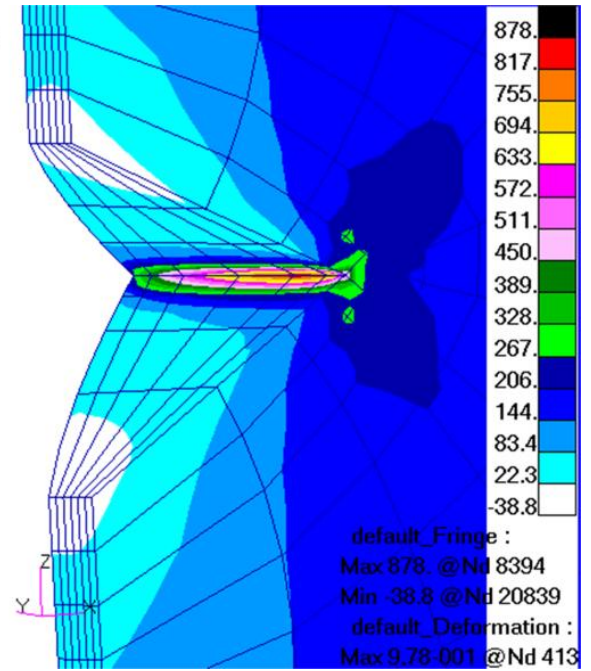

Fig. 8. Maximum principal stress distribution in cross-section of the blade with a sharp notch, (a) and stress state in the zone near notch (b), (I-st mode of transverse vibrations, amplitude of blade tip: $1 \mathrm{~mm}$, notch radius $r=0$, left deflection of blade)
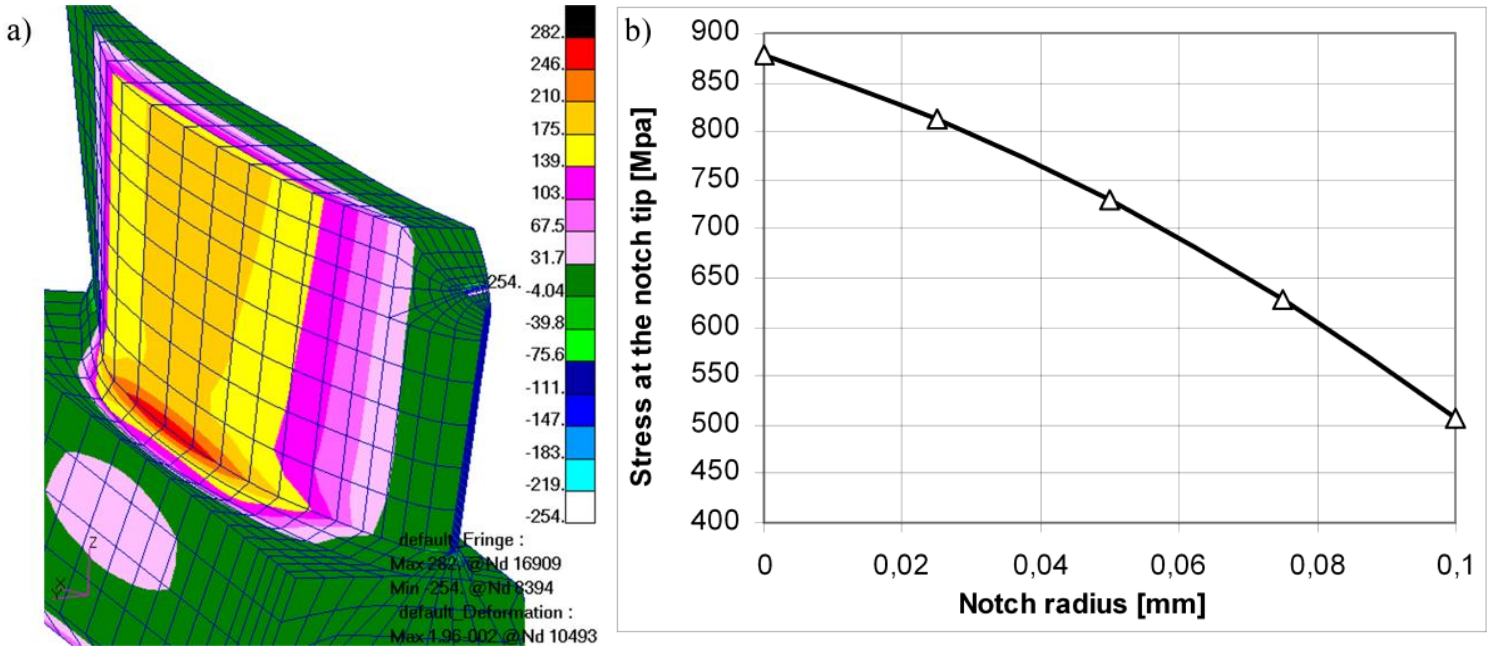

Fig. 9. Maximum principal stress distribution in cross-section of the blade with the notch (I-st mode of transverse vibrations, amplitude of blade tip: $1 \mathrm{~mm}$, notch radius $r=0$, right deflection of blade) (a) and the ol stress values in function of the notch radius $(b)$

As seen from Fig. 9b, the maximum tensioned stress depends on the notch radius. For the sharp notch (radius $\mathrm{r}=0 \mathrm{~mm}$ ), the maximum $\sigma_{1}$ stress in the notch zone achieves $878 \mathrm{MPa}$. When the notch radius increases, then the stress in the notch tip is lower. For example, if the notch has a radius of $0,075 \mathrm{~mm}$, then the stress decreases to about $630 \mathrm{MPa}$.

\section{FATIGUE PROCEDURES USED IN CRACK INITIATION ANALYSIS}

Purely static loading is rarely observed in modern engineering components or structures. The majority of structures involve parts subjected to fluctuating or cyclic loads. For this reason, design analysts must address the implications of the repeated loads, fluctuating loads, and rapidly applied loads. Such loading induces fluctuating or cyclic stress that often result in failure of the structure 
by fatigue. The compressor blade has a thin profile and, in consequence, a low bending stiffness. The fluctuation of the compressed air or rotation of the unbalanced shaft induce the fatigue (vibration) conditions.

In order to better understand the crack initiation analysis (known as strain-life or $\varepsilon-\mathrm{N}$ analysis), a few analytical fatigue procedures will be described in this chapter. The main procedures used in $\varepsilon-\mathrm{N}$ analysis are:

a) Basquin and Coffin-Manson equations used for description of the total strain-life ( $\varepsilon-\mathrm{N})$ curve;

b) Mean stress correction (i.e. Morrow or S-W-T methods);

b) Neuber elastic-plastic correction;

c) Rainflow counting;

d) Linear damage summation.

Several years ago Basquin observed that stress-life data may be represented by a straight line relationship when plotted using log scales $[19,20,21]$. The relationship could be expressed in terms of the true stress as:

$$
\sigma_{a}=\sigma_{f}^{\prime}\left(2 N_{f}\right)^{b}
$$

where:

$\sigma_{\mathrm{a}}$ - the true cyclic stress amplitude

$\sigma_{\mathrm{f}}$ - the regression intercept (fatigue strength coefficient)

$2 \mathrm{~N}_{\mathrm{f}}$ - number of half cycles (reversals) to failure

b - the regression slope (fatigue strength exponent)

The Basquin equation may be rewritten in terms of elastic strain amplitude:

$$
\varepsilon_{e}=\frac{\sigma_{a}}{E}=\frac{\sigma_{f}^{\prime}}{E}\left(2 N_{f}\right)^{b}
$$

where:

E - the Young modulus

$\varepsilon_{\mathrm{e}}$ - the elastic strain amplitude

Coffin and Manson $[20,21]$ independently proposed that the plastic component of a fatigue cycle may be also related to life by a simple power law:

where:

$$
\varepsilon_{p}=\varepsilon_{f}^{\prime}\left(2 N_{f}\right)^{c}
$$

$\varepsilon_{\mathrm{p}}$ - the plastic strain amplitude;

$\varepsilon^{\prime}{ }_{f}$ - fatigue ductility coefficient;

c - fatigue ductility exponent (regression slope).

More recent works, notably Morrow's, have indicated that the total strain amplitude is the sum of the elastic and plastic components, which may be better correlated to life. Figure 10 illustrates schematically the nature of the total strain-life curve. 


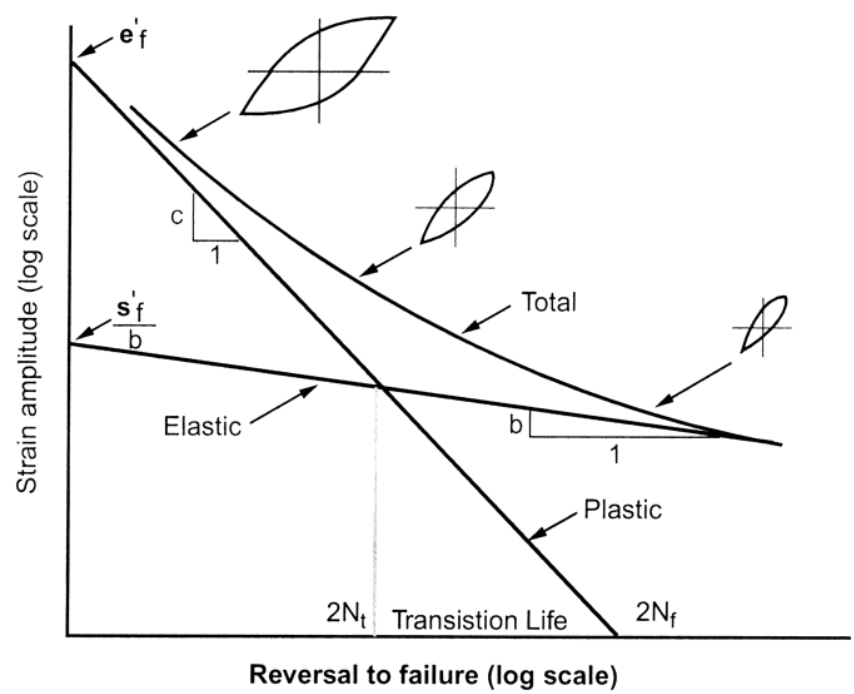

Fig. 10. Schematic total strain-life $(\varepsilon-N)$ curve used in crack initiation analysis with marked fatigue properties used in the fatigue theory. The strain is divided into elastic and plastic portion

From the mathematical point of view, this curve can be described by summing the Basquin and the Coffin-Manson component curve [19]:

$$
\begin{gathered}
\varepsilon_{t}=\varepsilon_{e}+\varepsilon_{p} \\
\varepsilon_{t}=\frac{\sigma_{f}^{\prime}}{E}\left(2 N_{f}\right)^{b}+\varepsilon_{f}^{\prime}\left(2 N_{f}\right)^{c}
\end{gathered}
$$

The most basic fatigue tests data is collected in the laboratory by means of testing procedures which employ fully reversed loading. In these cases, the stress ratio defined as $R=\sigma_{\max } / \sigma_{\min }$ equals -1. However, the most realistic service situations involve nonzero mean stress. It is, therefore, very important to know the influence that mean stress has on the fatigue process so that fully reversed laboratory data can be usefully employed in the assessment of real situations.

Morrow was the first to propose a modification to the baseline strain-stress curve which can account for the effect of the mean stress. He suggested that the mean stress could be taken into account when modifying the elastic part of the strain-life curve by the mean stress, $\sigma_{0}$.

$$
\varepsilon_{e}=\frac{\left(\sigma_{f}^{\prime}-\sigma_{0}\right)}{E}\left(2 N_{f}\right)^{b}
$$

The entire strain-life curve becomes:

$$
\varepsilon_{e}=\frac{\left(\sigma_{f}^{\prime}-\sigma_{0}\right)}{E}\left(2 N_{f}\right)^{b}+\varepsilon_{f}^{\prime}\left(2 N_{f}\right)^{c}
$$

Smith, Watson and Topper have proposed an original approach to account for the mean stress thorough a consideration of the maximum stress present in any given cycle. In this case, the damage parameter is taken to be the product of the maximum stress $\sigma_{\max }$, and the strain amplitude, $\varepsilon_{\mathrm{a}}$ of a cycle.

For fully reversed loading, the maximum stress is given by:

$$
\sigma_{\max }=\sigma_{f}^{\prime}\left(2 N_{f}\right)^{b}
$$

where:

$\sigma_{\max }$ - the maximum stress observed at the investigated point (node) of structure 
and by multiplying the strain-life equation by this term:

$$
\sigma_{\max } \times \varepsilon_{a}=\frac{\sigma_{f}^{\prime}}{E}\left(2 N_{f}\right)^{2 b}+\sigma_{f}^{\prime} \varepsilon_{f}^{\prime}\left(2 N_{f}\right)^{p+c}
$$

where:

$\varepsilon_{\mathrm{a}}$ - the strain amplitude

The Neuber's elastic-plastic correction method is commonly used to estimate elastic-plastic stresses and strains at the roots of notches on the basis of elastic stress analysis. The main assumption of the Neuber's method is that the elastic stresses and strains are looked up on the elastic line and then corrected to fall onto the cyclic stress-strain curve thus determining the elastic-plastic stresses and strains. The Neuber's elastic-plastic correction is based on the simple principle that the product of the elastic stress and strain should be equal to the product of elasticplastic stress and strain from the cyclic stress-strain curve. Then, the elastic-plastic strain can be determined with an iterative method.

The rainflow counting procedure is used in fatigue calculation to extract and count the number of stress (or strain) cycles in a complex time load history. The term "rainflow" is attributed to two Japanese scientists: Matsuiti and Ando [20] who invented this method. It is based on the concept of rain drops dripping down the pagoda roofs. The rain is visualized as running off each peak or valley. The end result of rainflow cycle counting is a set of constant amplitude signals and a count of the number of cycles.

The linear damage summation is used for summing the damage from various stress or strain cycles. A constant amplitude $\varepsilon-\mathrm{N}$ curve represents a set of tests at constant strain range $(\Delta \varepsilon)$ together with associated lives. Operation in the strain range $\Delta \varepsilon_{1}$ will result in failure in $\mathrm{N}_{1}$ cycles. Operation in the same strain range for a number of cycles lower than $\mathrm{N}_{1}$ (i.e. $\mathrm{n}_{1}$ ) will result in a smaller fraction of damage $\mathrm{D}_{1}$, which is often referred to as partial damage:

or

$$
\begin{aligned}
& D_{1}=\frac{n_{1}}{N_{1}} \\
& D_{i}=\frac{n_{i}}{N_{i}}
\end{aligned}
$$

The Palmgreen-Miner rule asserts that the partial damage of any strain range $\Delta \varepsilon_{1}$ is linearly proportional to the ratio of the number of operation cycles and to the total number of cycles that would produce failure at that strain level. According to Palmgreen-Miner, the failure is predicted if:

$$
\begin{gathered}
D=\frac{n_{1}}{N_{1}}+\frac{n_{2}}{N_{2 i}}+\cdots+\frac{n_{j}}{N_{j}}=1 \\
\sum_{i=1}^{j} \frac{n_{i}}{N_{i}}=1
\end{gathered}
$$

\section{FINITE ELEMENT CRACK INITIATION ANALYSIS}

To estimate the number of cycles to occurrence of the first fatigue crack in the blade, the program MSC Fatigue 9.0 was used. This program enables performing the $\varepsilon-\mathrm{N}$ analysis for the geometrically complicated numerical models defined by the user [20]. The program Fatigue needs (as the input data) the results obtained from the static stress analysis. In $\varepsilon-\mathrm{N}$ analysis, only the 
maximum principal stresses are considered. In the presented example, the Smith-Watson-Topper (S-W-T) mean stress method was used.

The fatigue calculations were performed for the load time history equivalent to one cycle of the transverse vibration (Fig. 11). Maximum value of 1 on the vertical axis is associated with the stress state obtained during the blade vibration (for one extreme deflection of the blade). In a node of the model the stress is e.g. tensioned. During the blade vibration, the bending theory can be applied. When the blade is in the opposite deflection, the stress is compressed (value of -1 on the vertical axis) in the same node of the model.

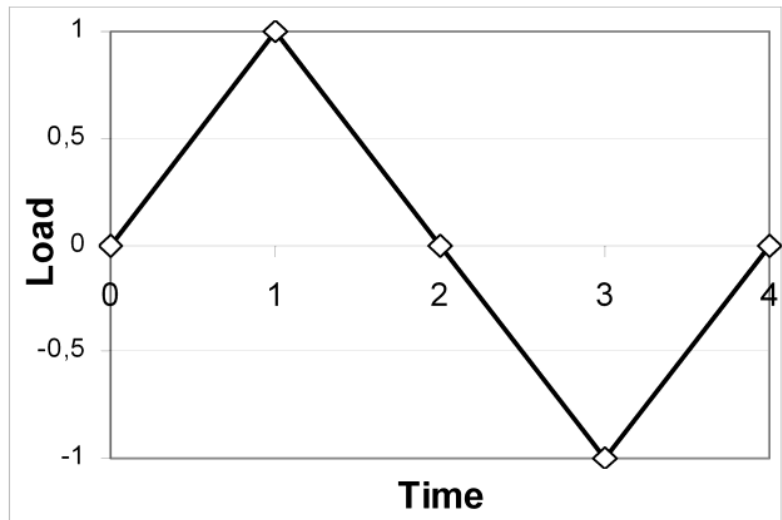

Fig. 11. Load time history equivalent to one cycle of the transverse vibration

The static (monotonic) properties of the EI-961 alloy were described in chapter 2. In order to perform a crack initiation analysis, additional material properties used in the fatigue calculations will be needed. It is often difficult to gain access to measured cyclic properties. For this reason, a lot of effort has been put into finding the ways to relate monotonic properties, of which there are abundant supplies, to cyclic properties. The approaches have been empirical but have provided some useful approximations.

One of the methods of approximating the strain-life relationship from monotonic properties was proposed by Manson and later modified by Muralidharan (Tab. 1). The procedure can be applied to any metal, especially to steel [20].

Baumel and Seeger [20, 21] have proceeded with an alternative approach based on the results of more than 1500 fatigue tests. This approach (Tab. 1) is limited to low and medium alloy steels and titanium alloys.

The ductility factor used in Baumel-Seeger method is calculated from equations:

$$
\begin{aligned}
& \alpha=1.0 \quad \text { for values of } \frac{R_{m}}{E} \leq 3 \times 10^{-3} \\
& \alpha=1,375-\left(\frac{125 R_{m}}{E}\right) \text { for } \\
& \frac{R_{m}}{E}>3 \times 10^{-3}
\end{aligned}
$$

In the presented fatigue analysis, the two approximation methods mentioned were used. Table 2 presents values of the fatigue properties of the EI-961 alloy calculated according to the BaumelSeeger and Muralidharan equations. In these calculations, the Young modulus were defined as 200 GPa while the UTS as $1090 \mathrm{MPa}$. The $\varepsilon-\mathrm{N}$ analysis was also performed for UTS $=1000 \mathrm{MPa}$ and $950 \mathrm{MPa}$ (only for the Baumel-Seeger solution). The strain-life curve plotted for the EI-961 alloy is presented in Fig. 12. 
Tab.1. Approximation of the fatigue properties on the basis of UTS $(\mathrm{Rm})$ and $\mathrm{E}$ values according to Muralidharan and Baumel-Seeger [21].

\begin{tabular}{|l|c|c|c|}
\hline \multicolumn{1}{|c|}{ Fatigue properties } & Symbol & Muralidharan & Baumel-Seeger \\
\hline Fatigue strength coefficient [Mpa] & $\mathrm{S}_{\mathrm{f}}^{\prime}$ & $0,623 \mathrm{R}_{\mathrm{m}} \times 0,823 \mathrm{E}^{0,168}$ & $1,5 \mathrm{R}_{\mathrm{m}}$ \\
\hline Fatigue strength exponent [-] & $\mathrm{b}$ & $-0,09$ & $-0,087$ \\
\hline Fatigue ductility exponent [-] & $\mathrm{c}$ & $-0,56$ & -0.58 \\
\hline Fatigue ductility coefficient [-] & $\varepsilon_{\mathrm{f}}^{\prime}$ & $0,0196\left(\mathrm{R}_{\mathrm{m}} / \mathrm{E}\right)^{-0,53}$ & $0,59 \alpha$ \\
\hline Cyclic strain-hardening exponent [-] & $\mathrm{K}^{\prime}$ & $\mathrm{S}_{\mathrm{f}}^{\prime} /\left(\varepsilon_{\mathrm{f}}^{\prime}\right)^{0,2}$ & $1,61 \mathrm{R}_{\mathrm{m}}$ \\
\hline
\end{tabular}

Tab. 2. Values of the fatigue properties of the EI-961 steel obtained on the basis of BaumelSeeger and Muralidharan solution (UTS=1090 MPa, G=200 GPa).

\begin{tabular}{|l|c|c|c|}
\hline \multicolumn{1}{|c|}{ Fatigue properties } & Symbol & Muralidharan & Baumel-Seeger \\
\hline Fatigue strength coefficient [Mpa] & $\mathrm{S}_{\mathrm{f}}^{\prime}$ & 1630,05 & 1635 \\
\hline Fatigue strength exponent [-] & $\mathrm{b}$ & $-0,09$ & $-0,087$ \\
\hline Fatigue ductility exponent [-] & $\mathrm{c}$ & $-0,56$ & $-0,58$ \\
\hline Fatigue ductility coefficient [-] & $\varepsilon_{\mathrm{f}}^{\prime}$ & 0,31043 & 0,4015 \\
\hline Cyclic strain-hardening exponent [-] & $\mathrm{K}^{\prime}$ & 1799 & 1799 \\
\hline
\end{tabular}

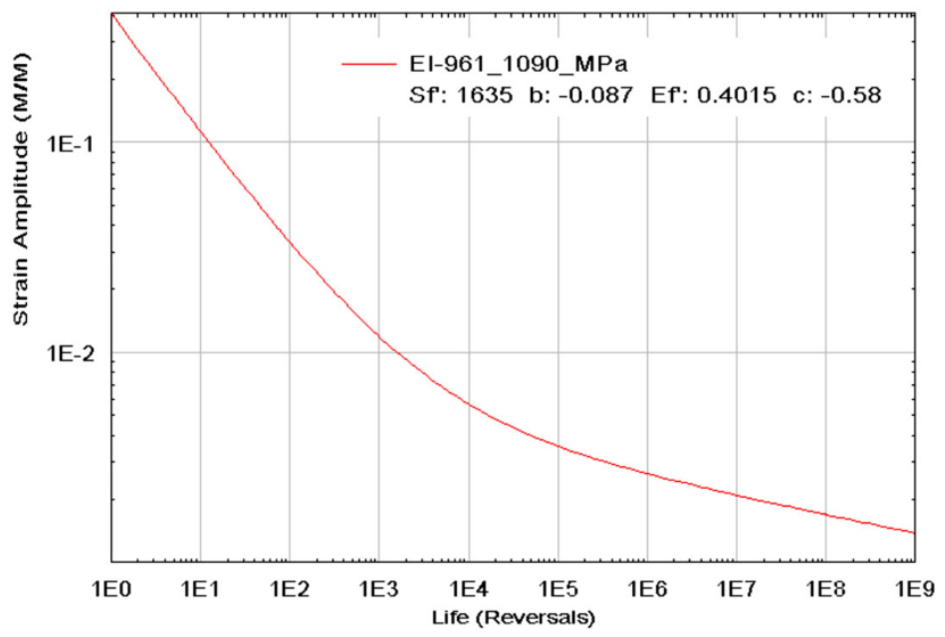

Fig. 12. Strain life ( $\varepsilon-N)$ plot for the EI-961 alloy

The results of $\varepsilon-\mathrm{N}$ analysis for the non-defected compressor blade which works in the resonance conditions are presented in Figs. $13 \div 15$. The results are displayed in the exponential form. In the zones displayed as red, the first fatigue cracks are expected. For example, when the amplitude of the blade tip during the I-st mode of vibration is $1,5 \mathrm{~mm}$, the estimated number of cycles to the first fatigue crack is $10^{6,13}$ (1348963 cycles) (Fig 13a). The first fatigue crack is understood in this case as the detectable crack, which has a length of about 1,5-2 $\mathrm{mm}$ [20]. There are two critical fatigue zones in the blade: the central part of the convex surface (Fig.13a) and the attack edge of the blade (Fig. 13b). Results of $\varepsilon$-N analysis for the blade vibrated with amplitude of $4 \mathrm{~mm}$ are presented in Figs 13c and 14a. As seen from these figures, the first crack can be initiated after $10^{3,67}$ (4677) cycles. The results presented in Figs. 13 and 14 were obtained on the basis of the Baumel-Seeger estimation. 
a)

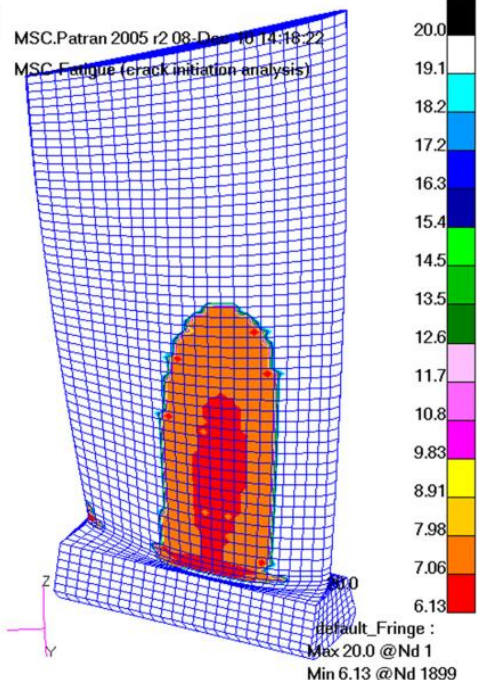

b)

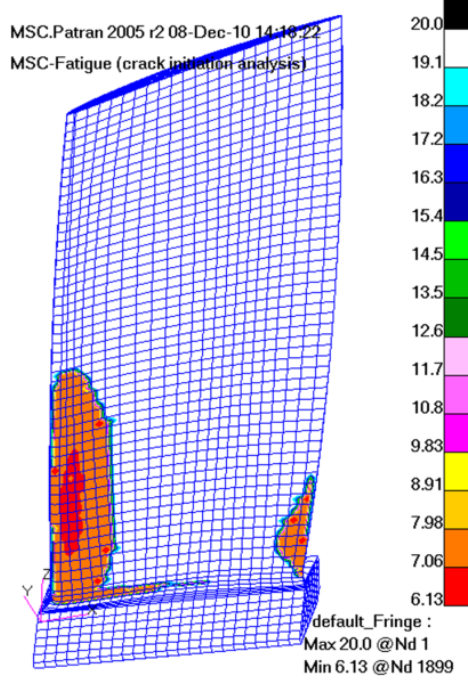

c)

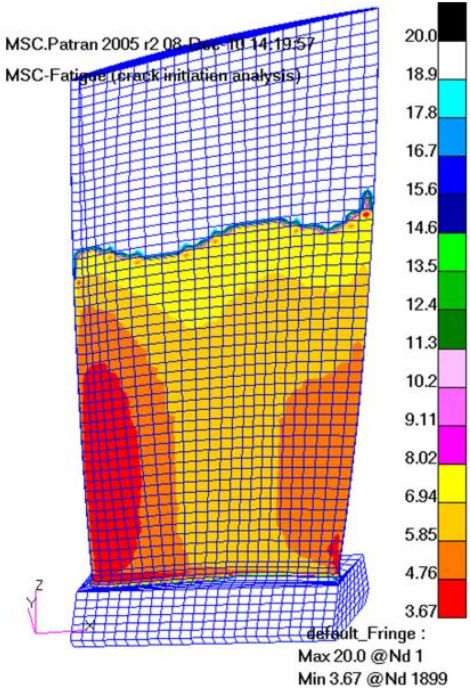

Fig. 13. Number of cycles at which the first fatigue crack can be initiated in the blade without preliminary defects. Blade vibration amplitude is equal $1,5 \mathrm{~mm}(a, b)$ and $4 \mathrm{~mm}(\mathrm{c})$

The result of $\varepsilon-\mathrm{N}$ analysis visualized on the cross-section of the blade vibrated with constant amplitude of $4 \mathrm{~mm}$ is presented in Fig. 14a. There are two red zones visible on the blade crosssection. Location of these zones overlaps with the areas where the cracks were detected during experimental fatigue analysis. The fatigue cracks in not-defected blades were initiated in the central part of the convex surface (Fig 14b) [6]. In a few cases (generally when the blades had any defects as corrosion pits or FOD), the crack was initiated from the attack edge of the blade (Fig. 14c). The experimental results presented in Fig. $14 \mathrm{~b}$ and 14c were made under the Polish Ministry of Science and Higher Education project no. N N - 504 346736. The results of the experimental tests performed for the blade without preliminary defects were described in detail in [6].
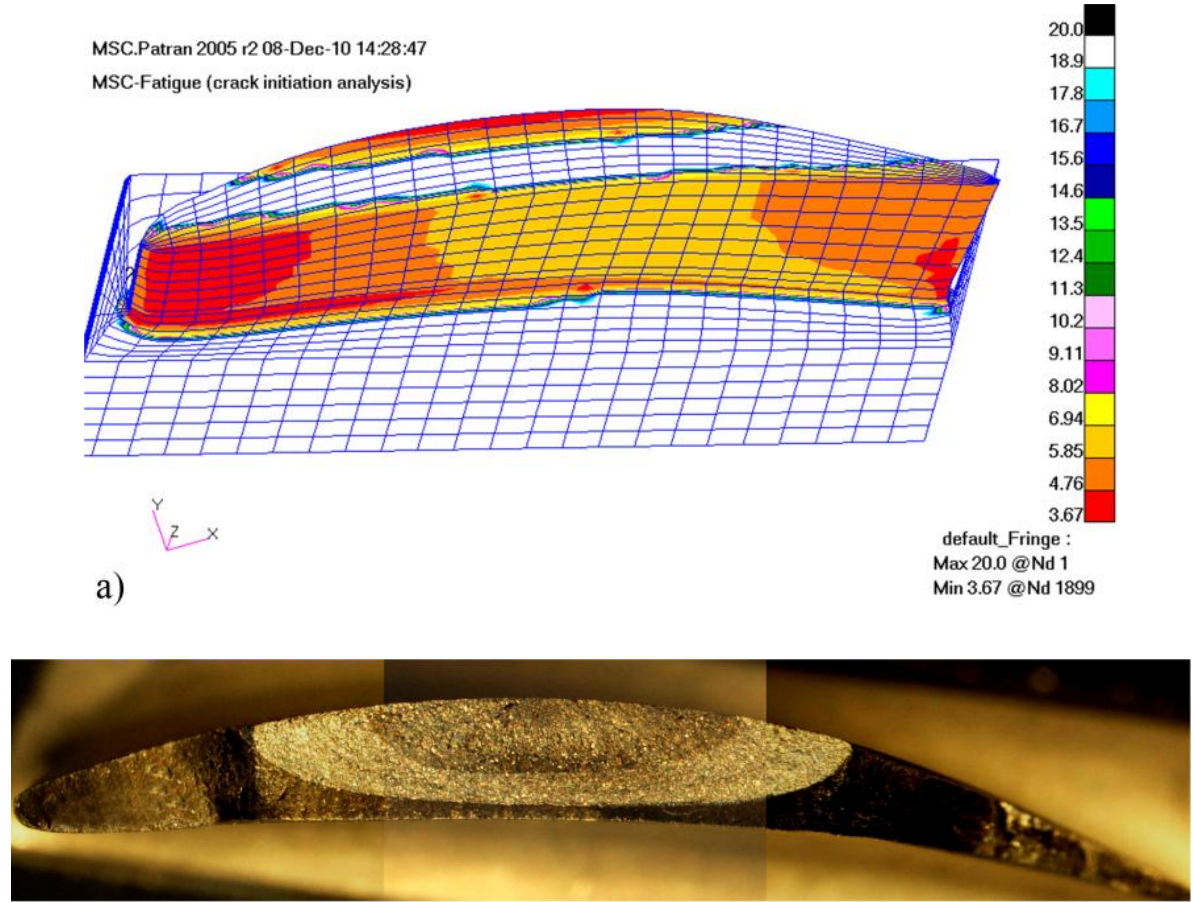

b) 


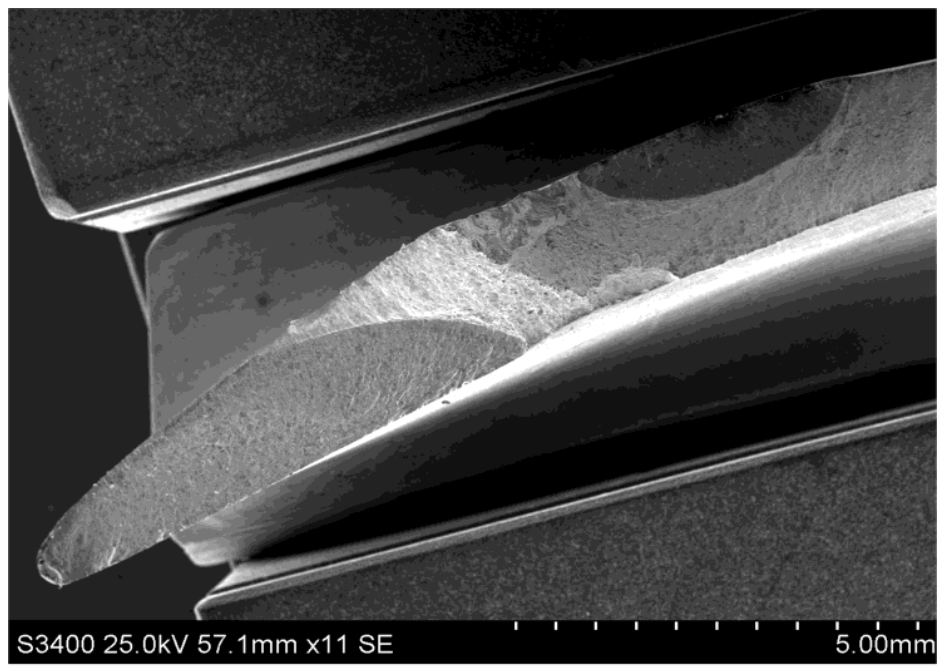

c)

Fig. 14. Result of $\varepsilon N$ analysis for the non-defected compressor blade (cross-section located $5 \mathrm{~mm}$ above the dovetail, amplitude of blade tip: $4 \mathrm{~mm}($ a). Fracture of blades with crack initiated from the central part of the convex surface [6] (b) and simultaneously from the attack edge and convex blade surface (c)

Tab. 3. Number of cycles to the first fatigue crack in the blade made from material with different UTS $(\mathrm{Rm})$

\begin{tabular}{|c|c|c|c|c|c|c|c|c|}
\hline & \multicolumn{6}{|c|}{ Baumel-Seeger } & \multirow{2}{*}{\multicolumn{2}{|c|}{$\begin{array}{c}\text { Muralidharan } \\
\mathrm{R}_{\mathrm{m}}=1090 \mathrm{MPa} \\
\end{array}$}} \\
\hline \multirow{3}{*}{$\begin{array}{c}\mathbf{R}_{\mathrm{m}}(\mathrm{UTS}) \\
\text { Blade tip } \\
\text { amplitude } \\
\text { [mm] } \\
\end{array}$} & \multicolumn{2}{|c|}{$R_{\mathrm{m}}=950 \mathrm{Mpa}$} & \multicolumn{2}{|c|}{$\mathrm{R}_{\mathrm{m}}=1000 \mathrm{Mpa}$} & \multicolumn{2}{|c|}{$\mathrm{R}_{\mathrm{m}}=1090 \mathrm{MPa}$} & & \\
\hline & \multicolumn{8}{|c|}{ Number of cycles to the crack initiation } \\
\hline & Exponent & Integer & Exponent & Integer & Exponent & Integer & Exponent & Integer \\
\hline 1 & 8,29 & 194984460 & 8,53 & 338844156 & 8,97 & 933254301 & 8,71 & 512861384 \\
\hline 1,5 & 6,8 & 6309573 & 7,04 & 10964782 & 7,37 & 23442288 & 7,02 & 10471285 \\
\hline 2 & 5,59 & 389045 & 5,79 & 616595 & 6,13 & 1348963 & 5,85 & 707946 \\
\hline 3 & 4,16 & 14454 & 4,27 & 18621 & 4,42 & 26303 & 4,25 & 17783 \\
\hline 4 & 3,45 & 2818 & 3,52 & 3311 & 3,67 & 4677 & 3,45 & 2818 \\
\hline
\end{tabular}

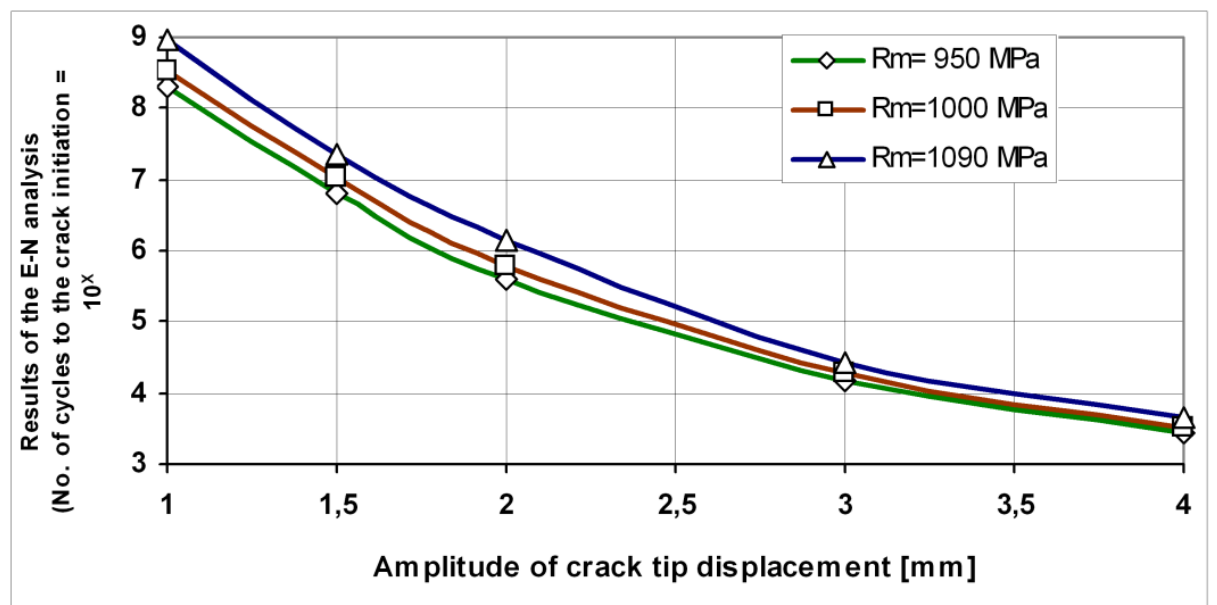

Fig. 15. Number of cycles (showed in exponential form) to the crack initiation in function of the vibration amplitude. Results for different UTS of EI-961 alloy. Baumeel-Seegel estimation of the material properties 
The FE fatigue computations were made for the following amplitude of the blade tip displacement: $1 ; 1,5 ; 2 ; 3$ and $4 \mathrm{~mm}$. Moreover, the influence of the ultimate tensile strength (UTS, $\mathrm{R}_{\mathrm{m}}$ ) of the EI-961 alloy on the fatigue life of blade was considered. In this analysis, fatigue properties were defined based on the following values of UTS: 950; 1000 and $1090 \mathrm{MPa}$. The results obtained for different vibration amplitudes and also for diversified UTS of the EI-961 alloy were shown in Tab. 3 and Fig.15. There are two forms used to describe the numbers of cycles: integer and exponential. For the exponential form, the base of power is 10 . The results presented in Fig. 13a and $13 \mathrm{c}\left(10^{6,13}=1348963\right.$ and $10^{3,67}=4677$ number of cycles $)$ are displayed in Tab. 3 with the use of bold fonts. As seen in Tab. 3, the Muralidharan fatigue material properties estimation gives lover values of the number of cycles to the crack initiation than the BaumeelSeegel solution. The difference between the two results is about $100 \%$.

When the blade has the notch (or mechanical defect such as FOD), the estimated number of cycles is much lower than computed for the brand-new blade without any defects. The numerical fatigue calculations for the following notch radiuses: $0 \mathrm{~mm} ; 0,025 \mathrm{~mm}$ and $0,075 \mathrm{~mm}$ were performed. In Fig. 16, the results of the $\varepsilon-\mathrm{N}$ analysis for the blade with the notch radius of 0,075 $\mathrm{mm}$ are presented. In this case, the estimated life is $10^{3,97}=9333$ number of cycles. When the notch is sharp ( $\mathrm{r}=0 \mathrm{~mm})$, a crack can initiate after about 2630 cycles (Tab. 4).

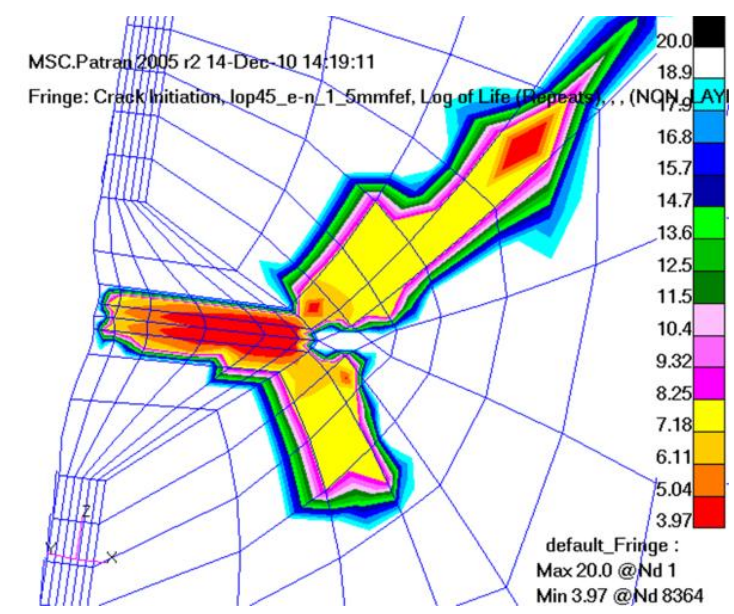

Fig. 16. Results of the $\varepsilon-N$ analysis for the notch area of the blade (notch with finite radius $r=0,075 \mathrm{~mm}$ ). Baumeel-Seegel method

Tab. 4. Number of cycles to crack initiation for different notch radius.

\begin{tabular}{|c|c|c|c|c|c|c|}
\hline \multirow{3}{*}{$\begin{array}{c}\text { Notch radius [mm] } \\
\text { Blade tip } \\
\text { amplitude }[\mathrm{mm}]\end{array}$} & \multicolumn{2}{|c|}{$\mathbf{r}=\mathbf{0}$} & \multicolumn{2}{|c|}{$\mathbf{r}=\mathbf{0 , 0 2 5}$} & \multicolumn{2}{|c|}{$\mathbf{r}=\mathbf{0 , 0 7 5}$} \\
\hline & \multicolumn{6}{|c|}{ Number of cycles to crack initiation } \\
\hline & Exponent & Integer & Exponent & Integer & Exponent & Integer \\
\hline 1 & 4,11 & 12882 & 4,29 & 19498 & 4,69 & 48978 \\
\hline 1,5 & 3,42 & 2630 & 3,62 & 4169 & 3,97 & 9333 \\
\hline 2 & 2,92 & 832 & 3,06 & 1148 & 3,37 & 2344 \\
\hline 3 & 2,13 & 135 & 2,25 & 178 & 2,49 & 309 \\
\hline 4 & 1,47 & 30 & 1,64 & 44 & 1,99 & 98 \\
\hline
\end{tabular}




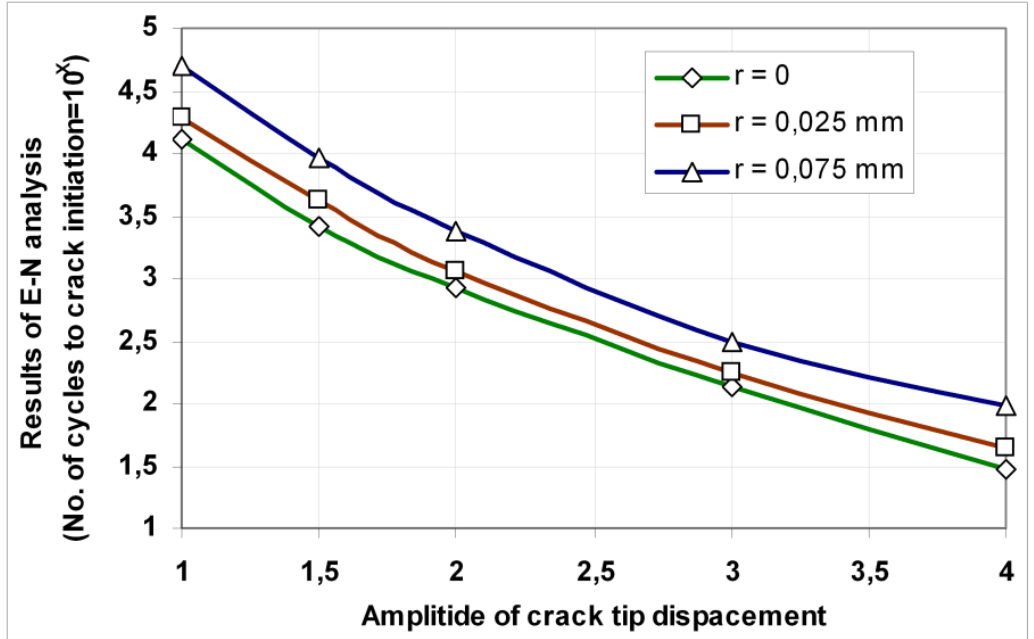

Fig. 17. Number of cycles to the crack initiation for the blade with a notch in function of the vibration amplitude, Baumeel-Seegel method

\section{EXPERIMENTAL VERIFICATIONS OF THE NUMERICAL FATIGUE RESULTS}

Experimental investigations of the crack initiation and crack propagation of the compressor blades were performed at Research and Development Laboratory for Aerospace Materials at the Rzeszów University of Technology. Before fatigue testing, each blade was horizontally mounted on the movable head of the vibrator (Fig. 18). After that, the head with the blade was entered into sinusoidal (harmonic) vibration. The investigation started with searching resonance frequency (for I-st mode of transverse vibration). During the test, both amplitude of vibration of the blade tip and the size (or existence) of the crack were periodically monitored. For the purpose of controlling the amplitude, the optical measuring microscope and alternatively the laser scanning vibrometer and the miniature $(0,2 \mathrm{~g})$ vibration piezoelectric sensor were used. Investigations were conducted for different intensities of vibration, defined by the amplitude of acceleration of the movable vibrator head. The fatigue tests were performed for the intensity of vibration between $5 \div 25 \mathrm{~g}$. During different intensity of vibration, diverse vibration amplitudes were obtained (Fig. 19).

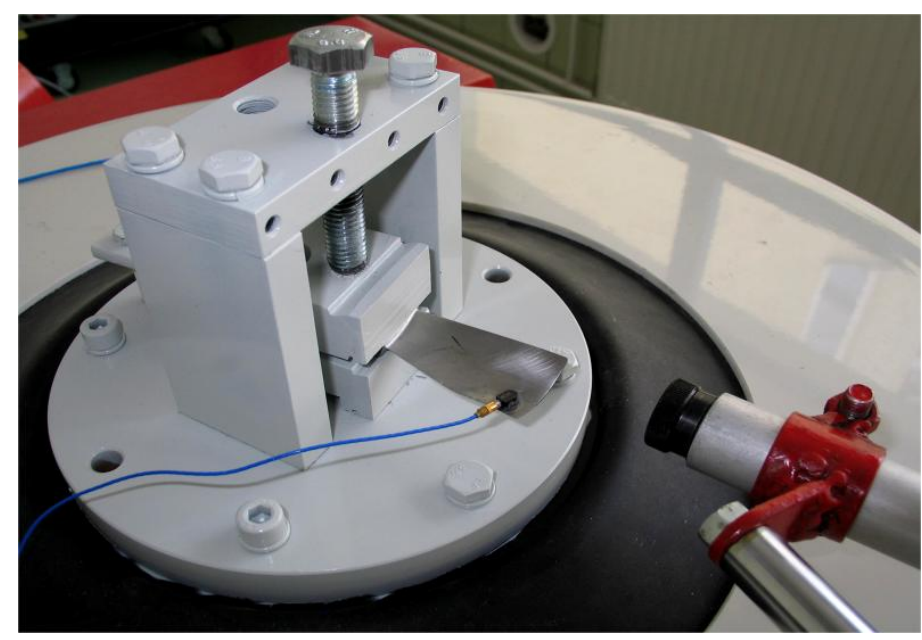

Fig. 18. Compressor blade fixed to the shaker during the fatigue test. Alternative measurement of the blade acceleration and displacement using the miniature $(0,2 \mathrm{~g})$ vibration sensor 


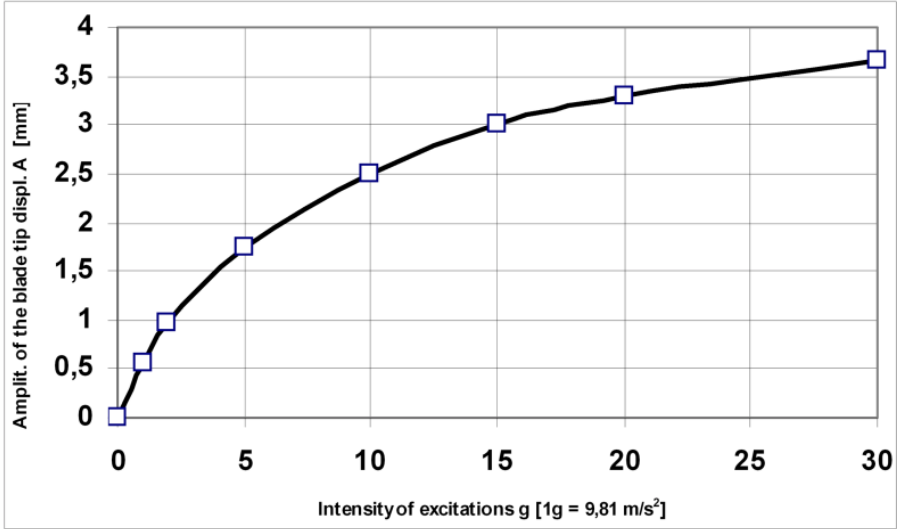

Fig. 19. Amplitude of the blade tip displacement (vibration amplitude) in function of the excitation intensity

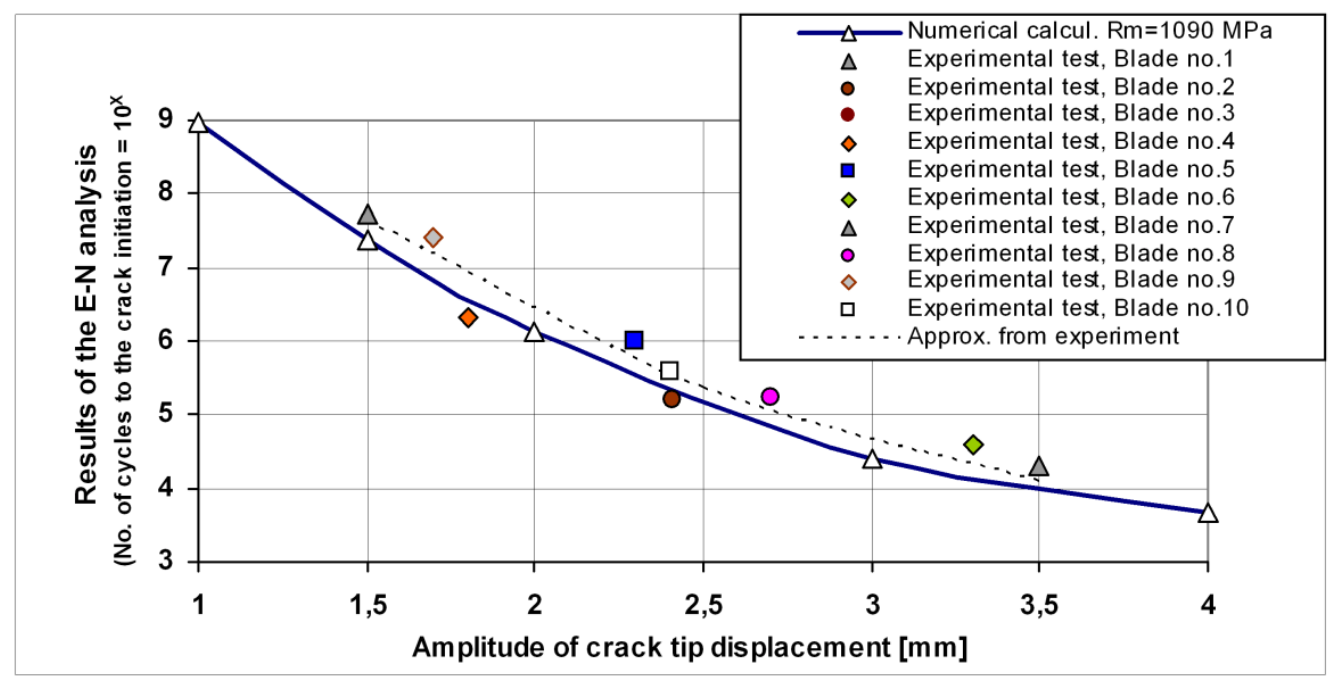

Fig. 20. Comparison of the experimental and numerical results (Baumeel-Seegel method) for the blade without preliminary defects.

In order to check the quality of the solution obtained from the numerical calculations, the comparison between FE and experimental results was made. As seen in Fig. 20, the experimental results for the non-defected blade have a wide dispersion for the blades tested in the same conditions. The dotted line represents average results of the experimental investigations. The number of cycles to crack initiation (computed according to the Baumeel-Seegel properties estimation) is about $100 \%$ lower than the results of experimental investigations performed for the same conditions. The estimated number of cycles to crack initiation obtained based on the Muralidharan method is about $200 \%$ lower than that obtained from the experimental tests.

The verification performed for the blades with the notches revealed that the numerical estimation gives about 3-5 times lower values of the number of cycles to first crack initiation than the experimental results. For example, the estimated number of cycles to crack initiation of the notched blade vibrated with amplitude of $1,5 \mathrm{~mm}$ (for notch radius $\mathrm{r}=0,075 \mathrm{~mm}$ ) is about 10000 $\left(0,1 \times 10^{5}\right.$ cycles) [Tab. 4]. By comparison, in the real (experimentally tested) blade vibrated with the same amplitude, the first crack was usually detected at about $0,3-0,5 \times 10^{5}$ cycles. The numerical fatigue results are conservative but the difference between the FE estimation and experimental results (from the science point of view) is too big. The next analysis should be performed to explain this divergence. 


\section{SUMMARY}

In this work, the complex stress and fatigue numerical analysis of the compressor blades was performed. In this analysis, the blades both without preliminary defects and those with notches were considered. In both cases, the influence of the blade vibration amplitude as well as UTS of the blade material on the number of cycles to the crack initiation were investigated. In the notched blades, the influence of the notch radius on the fatigue resistance of the blade was additionally examined. In all cases, the blade was tested in resonance conditions (I-st mode of the transverse vibrations). The finite element results were finally compared with the results of experimental vibration tests performed for both non-defected and notched blades.

Based on the analysis presented, the following conclusions can be formulated:

1. The quality of the used FE model was checked by convergence analysis. In this analysis, the resonant frequency $\left(f_{\text {rez }}\right)$ obtained from numerical calculations was compared with the value of $\mathrm{f}_{\mathrm{rez}}$ received during the experimental investigations. The result of this analysis showed that in the range of 2000-12000 finite elements, the value of $f_{\text {rez }}$ quickly decreased. In the presented case, satisfactory results can be obtained when the model has more elements than 13000 .

2. The maximum tensile stress in the blade vibrated with amplitude of $1 \mathrm{~mm}$ is about $248 \mathrm{MPa}$ (Fig. 6a). When the blade has a notch with the radius of $0 \mathrm{~mm}$, the computed stress near the notch tip is about 3 times larger ( $878 \mathrm{MPa}$, Fig. 8a). The most unfavorable case is when the blade is damaged by a sharp foreign object during the engine operation and the notch has a radius close to zero.

3. The maximum principal stress area in the non-defected blade (248 MPa, connection between the blade profile and the dovetail, Fig. 6) is not the same as the zone where the cracks were appearing during fatigue experimental tests (zone located between $1 \mathrm{~mm}$ and $15 \mathrm{~mm}$ above the dovetail, in the central part of the convex blade surface [6]). This difference can be caused by not accurate radius modeling in the zone of the profile-dovetail connection.

4. The estimated number of cycles to the crack initiation for the blade without the mechanical defects is about 1,4 million (mln), (for the blade vibrated with amplitude of $2 \mathrm{~mm}$ ). The results of $\varepsilon-\mathrm{N}$ analysis strongly depend on the amplitude of the blade tip displacement. For larger amplitudes, the difference between the actual stress in the blade and the UTS of the blade material decreases. When the amplitude increases to the value of $4 \mathrm{~mm}$, the fatigue durability of the blade decreases to about 4700 cycles (Tab. 3).

5. The estimated fatigue life of the blade with a notch or FOD is very low (Fig. 17, Tab. 4). For the notched blade vibrated witch amplitude of $1 \mathrm{~mm}$ (for notch radius $\mathrm{r}=0 \mathrm{~mm}$ ), the estimated number of cycles to the crack initiation is 12882. It means that the blade vibrated with resonant frequency equal to about $800 \mathrm{~Hz}$, will work for only 12 seconds to the first crack appearance. When the radius of the notch is $0,075 \mathrm{~mm}$, the crack will initiate after about 49000 cycles.

6. The results of $\varepsilon-\mathrm{N}$ analysis strongly depend on the Ultimate Tensile Strength (UTS, $\mathrm{R}_{\mathrm{m}}$ ) of the blade material. The estimated number of cycles to the crack initiation (for the following parameters: UTS $=1090 \mathrm{MPa}$, vibration amplitude of $2 \mathrm{~mm}$, the Baumel-Seeger approximation, not defected blade) is about $1,4 \mathrm{mln}$. cycles. When the UTS decreases to $1000 \mathrm{MPa}$, the initiation process begins at $0,6 \mathrm{mln}$ cycles. The result of $\varepsilon-\mathrm{N}$ analysis for UTS $=950 \mathrm{MPa}$ is about 0,4 mln of cycles. The real UTS of the EI-961 alloy depends on its heat treatment. The quality of the heat treatment should be controlled during manufacturing process because of its significant influence on the fatigue life. 
7. The observed variation of the experimental results is more than $300 \%$ (Fig. 20). In the fatigue experimental analysis this dispersion is typical. Thus, it is difficult to compare the experimental and numerical results because of the small number of experimental tests (only 10 investigated blades without preliminary defects and 10 with notches).

8. Based on the obtained results, it seems that the numerical fatigue calculations are conservative. The results of calculations for the non-defected blade (using the Baumeel-Seegel method) are about $100 \%$ lower than the real number of cycles to the crack initiation obtained in the experiment. The Muralidharan method gives more significant errors (200\%) than the BaumeelSeegel properties estimation.

9. The results divergence could be caused by inaccurate fatigue material properties estimation. The experimental tests (or a different analytical method to obtain these properties) should be performed before next analysis.

10. The blade during manufacturing process was shoot peened. The shoot peening introduces the compressive (residual) stress into the surface layer of the material. Superposition of the actual (tensioned) stress with the residual (compressed) stress causes that the fatigue life of the shoot peened components is longer. In the $\varepsilon-\mathrm{N}$ analysis, the influence of the residual stresses was not considered. This fact could be the reason for divergence between the numerical and experimental results.

11. The divergence between numerical and experimental fatigue results for the blades with notches is very big (300-500\%). One of possible reasons for the low fatigue resistance estimation is that during the notch creation process (the notch was created when a sharp object hit the attached edge of the blade) a very large plastic strain is observed. In consequence, a large zone of compressive (residual) stresses is formed in the notch vicinity. The influence of the residual stresses on the fatigue life of the blade should be also investigated.

\section{ACKNOWLEDGEMENT}

This work was supported by Polish Ministry of Science and Higher Education (Project No. N N 504 346736).

\section{REFERENCES}

[1] Lourenço, N.J., Graça, M.L.A., Franco, L.A.L. \& Silva, O. M. M. (2008). Fatigue failure of a compressor blade. Engineering Failure Analysis. 15(6), 1150 - 4.

[2] Kermanpur, A., Sepehri Ami, H., Ziaei-Rad, S., Nourbakhshnia, N. \& Mosaddeghfar, M. (2008). Failure analysis of Ti6Al4V gas turbine compressor blades. Engineering Failure Analysis. 15(6), 1052 - 64.

[3] Silveira, E., Atxaga, G. \& Irisarri, A.M. (2008). Failure analysis of a set of compressor blades. Engineering Failure Analysis. 15(6), 666 - 674.

[4] Poznanska, A., Sniezek, M. \& Wierzbinska, M. Pitting corrosion - main factor generating fracture of the compressor of aeroengine blades under operation. In: Proceedings of IX conference. Turbomachinery, Rzeszow; 2003 [in Polish].

[5] Witek, L.; Wierzbińska, M. \& Poznańska, A. (2009). Fracture analysis of compressor blade of a helicopter engine. Engineering Failure Analysis. 16(5), 1616-1622.

[6] Witek, L. (2009). Experimental crack propagation and failure analysis of the first stage compressor blade subjected to vibration. Engineering Failure Analysis. 16(7), 2163-2170.

[7] Troshchenko, V.T. \& Prokopenko, A.V. (2000). Fatigue strength of gas turbine compressor blades. Engineering Failure Analysis. 7(3), 209-220. 
[8] Myounggu Park, Young-Ha Hwang, Yun-Seung Choi, Tae-Gu Kim. (2002). Analysis of a J69-T-25 engine turbine blade fracture. Engineering Failure Analysis. 9(5), 593 - 601.

[9] Kyo-Soo Song, Seon-Gab Kim, Daehan Jung, Young-Ha Hwang. (2007). Analysis of the fracture of a turbine blade on a turbojet engine. Engineering Failure Analysis. 14(5), 877 883.

[10] Vardar, N. \& Ekerim, A. (2007). Failure analysis of gas turbine blades in a thermal power plant. Engineering Failure Analysis.14(4), 743 - 749.

[11] Xiaolei Xu \& Zhiwei Yu. (2007). An investigation on the failed blades in a locomotive turbine. Engineering Failure Analysis. 14(7), 1322-1328.

[12] Yu-jiang Xie, Mao-cai Wang, Ge Zhang, Min Chang. (2006). Analysis of superalloy turbine blade tip cracking during service. Engineering Failure Analysis. 13(8), 1429-1436.

[13] Witek, L. (2006). Failure analysis of turbine disc of an aero engine. Engineering Failure Analysis. 13(1), 9 - 17.

[14] Witek, L., Kowalski, T. \& Mamrowicz, J. Numerical stress and fatigue analysis of the first stage of turbine for helicopter engine. In: Proceedings of International Conference on Aeronautical Fatigue, 16-18 May 2007. Napoli.

[15] MSC Corporation (2004). MSC-PATRAN User_s Manual, ver. 2004. Los Angeles: MSC Corporation.

[16] Michailov, P.B. (1961). Sprawocznik po Metaliczeskim Matierialam Turbino-i Motorostroenija. Petersburg.

[17] Abaqus Inc. (2007). ABAQUS Users Manual, ver. 6.7. Abaqus Inc.

[18] Kocanda S. \& Szala J. (1985). Podstawy obliczeń zmęczeniowych. Warszawa: PWN (in Polish).

[19] MSC Corporation (2000). MSC Fatigue 9.0 Users Manual - Fatigue theory, Los Angeles: MSC Corporation.

[20] Meggiolaro M.A. \& Castro, J.T.P. (2004). Statistical evaluation of strain-life fatigue crack initiation predictions. International Journal of Fatigue. 26(2004), 463 - 476. 